\title{
THE RAMAURA SYNTHETIC RUBY
}

\author{
By Robert E. Kane
}

A new synthetic ruby grown by a process involving high-temperature flux with spontaneous nucleation has been developed. This new synthetic ruby is currently commercially available under the trade name Ramaura. The Ramaura synthetic exhibits some internal characteristics that are distinctly different from those observed previously in commercially available synthetic rubies. Some of the Ramaura synthetic rubies are readily identifiable, while others could present a serious cause for concern in the world's ruby markets and call for extreme care on the part of gemologists in the examination of rubies. In this article, the author examines in detail the gemological properties of the Ramaura synthetic ruby and discusses means of identifying this new synthetic.

\section{ABOUT THE AUTHOR}

Mr. Kane is research and gem identification supervisor of GIA's Gem Trade Laboratory, Inc., Los Angeles, California.

Acknowledgments: The author wishes to thank Peter Flusser and the staff of the Ramaura division of Overland Gems, inc., for the loan of the synthetic material; Shane McClure, Robert Crowningshield, and Dr. George Rossman for useful suggestions; John Koivula for his help in photographing figures 17 and 24, and in selecting the other photomicrographs; Chuck Fryer for performing the short-wave U.V. transparency tests and supplying figure 5; Dr. Anthony R. Kampf for providing the crystal morphology descriptions and preparing figure 2; and George Bosshart, Dr. H. A. Hänni, Dr. W. B. Stern, and $B$. Suhner for the spectrophotometric examinations:

(c) 1983 Gemological Institute of America
Tn 1877, Edmund Frémy and Charles Feil reported their discovery of a technique for crystallizing small, thin transparent rubies from a flux. With the introduction and successful marketing of Verneuil (flame-fusion) synthetic rubies in the early 1900s, however, there was little incentive to further develop other methods of synthesizing ruby. It was not until the early 1960 s, when the use of synthetic ruby crystals for laser research was initiated (Maiman, 1960), that the study of the flux grow th of ruby was vigorously resumed in an attempt to produce crystals possessing higher optical qualities than those found in the Verneuil product.

One of the first modern flux methods of producing synthetic corundum was described by J. P. Remeika in U.S. Patent 3,075,831, recorded January 29, 1963. Since then, more than 30 different processes for the flux grow th of corundum--each using slightly different conditions for growth and different fluxes-have been reported (Nassau, 1980). Many of these methods were intended specifically for industrial applications / such as for lasers, semi-conductors, etc.) and not for use as synthetic gemstones.

Until recently there were only two major producers of flux-grown synthetic rubies that were commercially available for use as gemstones: Chatham Created Gems, Inc., of San Francisco, California, and Kashan, Inc., of Austin, Texas. A relatively new synthetic ruby developed by Professor P. O. Knischka of Styer, Austria (Knischka) and Gübelin, 1980; Gübelin, 1982) is now commercially available in the form of rough crystals (P. O. Knischka, personal communication, 19831. Kyocera International, Inc., of Kyoto, Japan, is also producing and marketing faceted synthetic rubies, under the trade name Inamori, but the method of synthesis has not yet been confirmed (it does not show characteristics of flux growth). Likewise, synthetic rubies grown by the Verneuil method are still available on the market. 


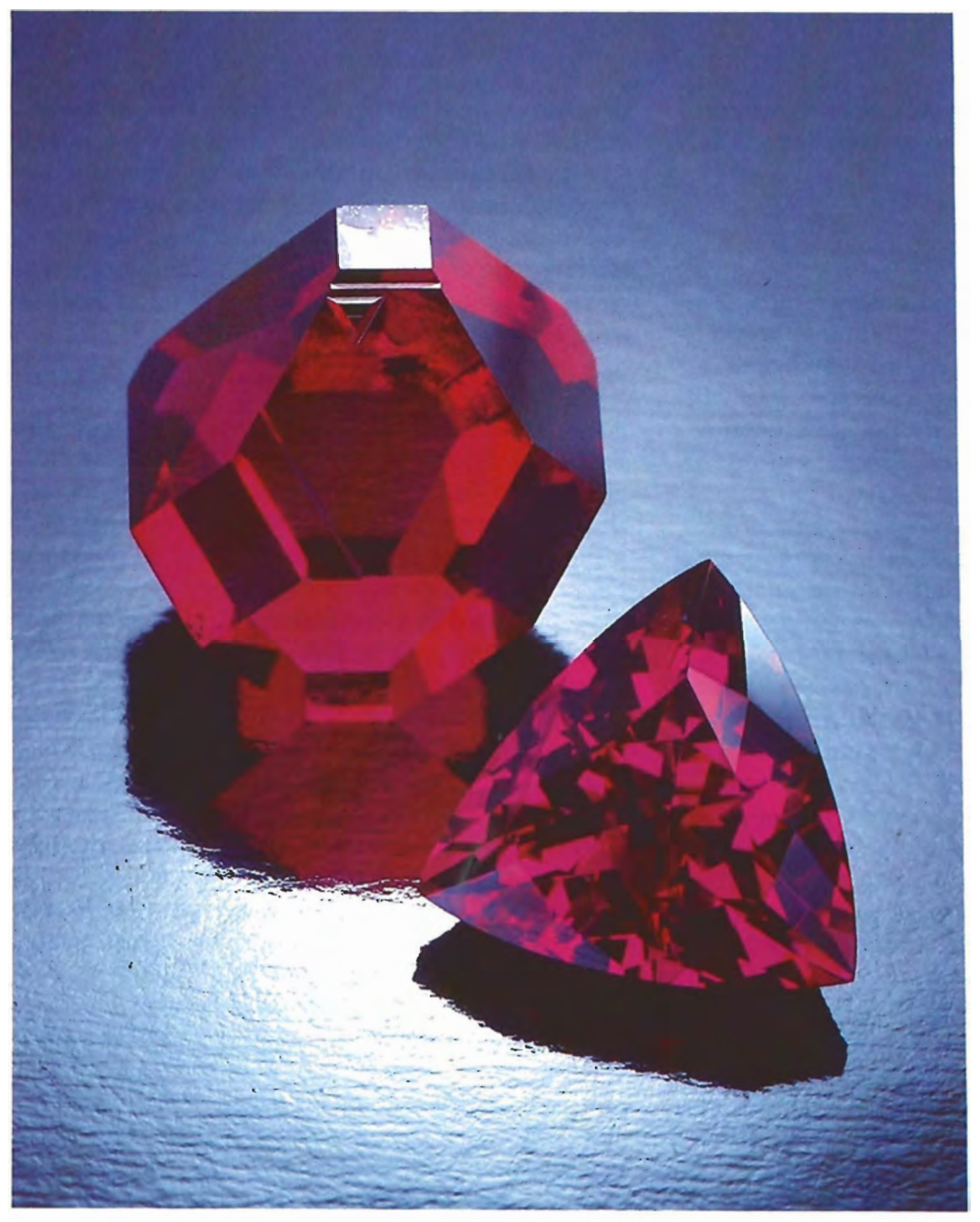

Figure 1. Ramaura synthetic rubies: the 8.77-ct uncut specimen is a rare example of a large, nearly equidimensional rhombohedral crystal; the faceted stone weighs $3.67 \mathrm{ct}$. Photo ${ }^{\text {(1) }} 1983$ Tino Hammid.
In early 1983, the availability of yet another flux-grown synthetic ruby intended specifically for use as synthetic gem material was announced by the Ramaura division of Overland Gems, Inc., of Los Angeles, California (figure 1). The distributor reports that this new synthetic ruby is being marketed under the trade name Ramaura, primarily in the form of faceted stones. The Ramaura firm also reports that they intend to market lower-grade (heavily included) rough material for fashioning into beads and cabochons, as well as single crystals and crystal clusters (Peter Flusser, personal communication, 1983).

The Ramaura synthetic ruby was developed by a southern California chemist who has extensive experience in industrial crystal growth. Although specific details of the Ramaura process have not been disclosed, we do know that it involves a high-temperature flux method with spontaneous nucleation.

The purpose of this article is to first examine the mode of synthesis of the Ramaura ruby and then present the gemological properties of the material, as well as means of distinguishing this synthetic ruby from its natural counterpart. The author conducted this study by careful examination of 160 faceted Ramaura synthetic rubies of various shapes and cuts, which ranged in weight 
from 0.15 to $7.98 \mathrm{ct}$, and 82 Ramaura synthetic ruby crystals, which ranged in weight from 0.21 to $86.73 \mathrm{ct}$.

\section{SYNTHESIS OF THE RAMAURA SYNTHETIC RUBY}

One important difference in the current growth process of the Ramaura synthetic ruby from that of other commercially available flux-grown synthetic rubies is that seeds are not used. Specifically, the Ramaura process allows spontaneous nucleation (also referred to as self-nucleation) of crystals as the flux melt cools slowly.

For example, Chatham synthetic rubies are grown on seed crystals or seed plates (as reported by Thomas Chatham, personal communication, 1983, and from the author's study of rough materials), which may be either natural or synthetic corundum /synthetic ruby is commonly used at the present time). The seeds are selectively chosen crystals or portions of crystals that are added to the flux-melt mixture, either suspended in the mixture itself or placed in one of a variety of positions within the crucible. The use of seeds enables better control over the growth rate as well as over the perfection and orientation of the crystals grown. The growth rate of the crystal is directly proportional to the surface area of the seed. Since an individual crystal can result in any of several different proportions, the predisposition of the seed can also help modify the growth of the crystal to produce a somewhat predetermined shape and size. Consequently, the use of seeds gives the manufacturer greater control over the end result, that is, the ability to produce larger, cuttable crystals at a faster rate of growth and with proportions that yield faceted stones with desirable weight retention percentages.

In contrast, spontaneous nucleation often produces crystals that grow in uncontrolled directions and yields several different crystal habits (which will be addressed later in this article). One important advantage of this type of growth, however, is that the tabular crystals that are used most often for faceting material contain areas that are much less included than those synthetic rubies grown by flux methods that use seeds. Interestingly, Kashan has reported using spontaneous nucleation as well as seed crystals (Mallas, 1979), although this may be a case where spontaneous nucleation has occurred in the same crucible where seeds have been used, which is common.
Because crystal growth by spontaneous nucleation is much less controllable, the process often results in crystal clusters that are too thin or rhombohedral crystals that are too small to be fashioned into gemstones. Also, the growth time for large cuttable crystals with spontaneous nucleation is often greater than it would be if seeds were employed.

\section{CRYSTAL MORPHOLOGY}

As a result of its unusual growth process, the Ramaura synthetic ruby exhibits several different forms. To facilitate the identification of synthetic ruby rough grown by the Ramaura method, a discussion of crystal morphology is provided here. The following morphology descriptions were prepared by Dr. Anthony R. Kampf, curator of mineralogy at the Los Angeles County $\mathrm{Mu}-$ seum of Natural History.

Ramaura synthetic ruby crystals grow in three basic habits. In the first, nearly equidimensional crystals are found attached to the crucible walls. An idealized drawing of one such crystal is shown in two views in figure 2. An exceptional example of a Ramaura synthetic ruby crystal exhibiting this type of nearly equidimensional rhombohe$\mathrm{dral}$ form is shown in figure 1 . Only three crystallographic forms (sets of faces) have been observed on these crystals. The rhombohedral forms $\mathrm{R}(01 \overline{1} 2)$ and $\mathrm{r}(10 \overline{\mathrm{l}} \mathrm{l})$ are generally predominant, and the basal c(0001) form is subordinate. Crystals in this habit are remarkably perfect and inclusion-free, with the exception of textural growth features and color zoning; however, they seldom exceed $1 \mathrm{~cm}$ in maximum dimension.

In the second habit, ruby crystals growing on the melt surface develop as clusters of very thin plates. The c $(0001)$ form is universally predominant and is bounded by a combination of $r(01 \overline{1} 2)$, $\mathrm{d}(10 \overline{1} 2)$, and $\mathrm{n}(22 \overline{4} 3)$ forms. The plates typically range from 1 to $3 \mathrm{~cm}$ in diameter and from 0.01 to $0.30 \mathrm{~cm}$ in thickness. Flux is often trapped along the edges of the rapidly growing plates, resulting in lines of inclusions paralleling the bounding faces. One cluster that consisted of very thin, clean plates measured nearly $9 \mathrm{~cm}$ in length and 2 $\mathrm{cm}$ in height. This crystal cluster also exhibited a very curved nature that reflected the curvature of the crucible.

The crystals that lend themselves most to faceting, the third group, are similar in morphology to the plates described above, but attain sig- 


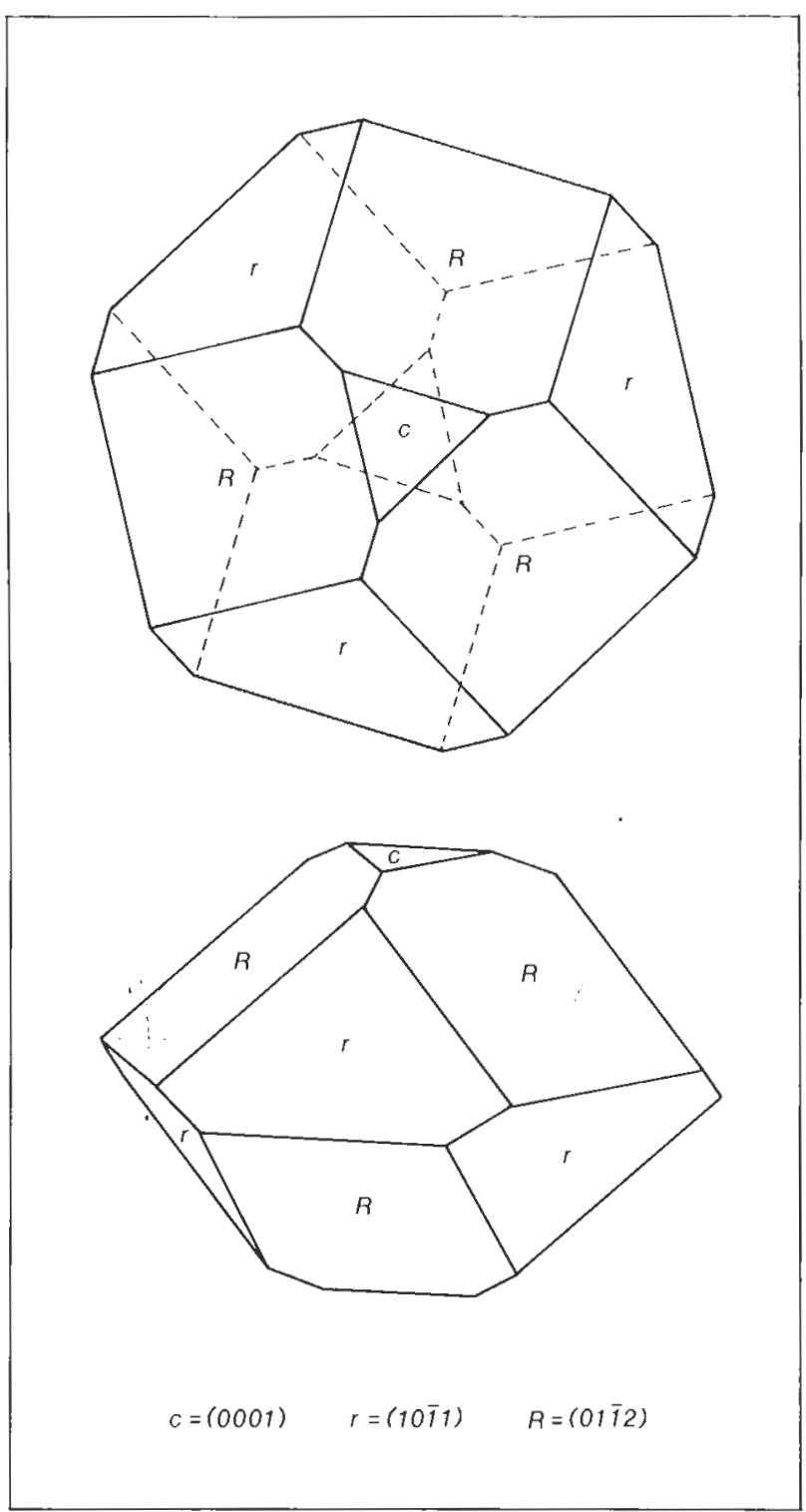

Figure 2. An idealized drawing of the crystal morphology of a nearly equidimensional rhombohedral Ramaura synthetic ruby crystal. Drawing by Dr. Anthony R. Kampf.

nificantly greater thickness. They may be up to 4 $\mathrm{cm}$ across and are usually between 0.5 and $3.0 \mathrm{~cm}$ thick (occasionally they occur thicker). These ruby crystals grow attached to the sides and bottom of the vessel and consequently may exhibit a slightly curved attachment surface. They usually contain some trapped flux, but very large areas are free of inclusions except for growth features and color zoning.

\section{GEMOLOGICAL CHARACTERISTICS}

The new Ramaura synthetic ruby exhibits many characteristics that are typical of flux-grown synthetic rubies, in addition to some that are distinctly different from any observed thus far in other commercially available synthetic rubies. In some situations, the gemologist will have to carefully examine several of the gemological properties and meticulously study the frequently observed subtle internal characteristics to conclusively identify this new synthetic ruby. The following discussion examines in detail the gemological characteristics of the Ramaura synthetic ruby. These characteristics are summarized in table 1.

Visual Appearance. As the faceted Ramaura synthetic rubies are examined with the unaided eye, several features can be noted, in particular, color, transparency, and clarity.

With regard to color, the Ramaura synthetic rubies examined by the author varied from nearly pure red, to slightly orangy red, to slightly purplish red and purple red; all varied in saturation from moderate to vivid. Also examined were faceted stones that exhibited slight to moderate saturations of light red secondary hues (thus, giving a distinct pink appearance). Figure 3 shows many of the hues that the Ramaura synthetic ruby may exhibit. As is the case with the Kashan synthetic rubies, the color range of the rubies synthesized by Ramaura overlaps to some degree with the wide range of colors produced in their natural counterparts from several different geographical localities.

Also very evident to the unaided eye in many of the faceted Ramaura synthetic rubies is an unusual degree of transparency. This is perhaps caused in part by the unique growth process. Since none of the growth is forced (as it is in techniques involving the use of seeds), fewer impurity ions are trapped, so there are fewer dislocations or defects in the crystal lattice. The growth process also minimizes the inclusions that are visible to the unaided eye or observed under the gemological microscope.

The clarity of the faceted Ramaura synthetic rubies, when examined with the unaided eye, varies from stones that appear to be completely free of inclusions to those that have areas of visible flux inclusions and still others that exhibit only slight textural growth features and color 
zoning. The growth features and color zoning are most easily observed when the faceted stone is tilted at an angle.

Optic Axis Orientation. With the Ramaura synthetic ruby, the direction of optic axis orientation is variable. Since the synthetic growth process involves spontaneous nucleation, which produces many different external crystal forms, the faceted stones can be cut with various orientations to obtain the greatest weight retention. In the faceted stones examined by the author, the direction of the optic axis orientation varied greatly from stone to stone: in some it was parallel to the table, in some perpendicular to the table, and in others at various angles between these two.

Some faceted synthetic rubies, such as many produced by the Verneuil process, are typically oriented with the optic axis nearly parallel to the table. Specifically, Verneuil boules often split lengthwise to ease internal strain (Barta, 1957), which produces rough that yields the greatest weight retention when the table of the faceted stone 'is' oriented parallel to the length of the boule: With this orientation, the optic axis is usually only about $30^{\circ}$ from parallel to the table (R. T. Liddicoat, Jr., personal communication, 1983). It has been reported that natural ruby rough, in contrast, often yields the most attractive color and the greatest weight retention when the optic axis is oriented perpendicular to the table (Liddicoat, 1977).

The fact that any natural or synthetic ruby could be fashioned into a faceted stone with any one of several possible optic axis orientations means that the direction of this orientation should not be used as even a vague indicator of natural or synthetic origin.

Refractive Indices and Birefringence. Refractive indices were determined using a GEM Duplex II refractometer in conjunction with a monochromatic light source equivalent to sodium vapor. Testing revealed that most of the Ramaura synthetic rubies showed refractive indices of $\omega=1.762$ and $\varepsilon=1.770$, while some of the material had values of $\omega=1.760$ and $\varepsilon=1.768$ (this variation is also observed in natural ruby|. These values give an optic character of uniaxial negative and a birefringence of 0.008

Pleochroism. A calcite dichroscope was used to examine this property. In the faceted Ramaura synthetic rubies examined by the author, the dichroic effect was observed as moderate to strong in various hues depending on the color of the stone being examined. Commonly observed was dichroism that ranged in various saturations of the following hues: reddish purple and purplish red parallel to the c-axis, and orangy pink loccasionally higher saturations of pink made the

TABLE 1. The gemological properties of faceted Ramaura synthetic ruby

\begin{tabular}{|c|c|c|c|c|c|c|c|}
\hline \multirow{2}{*}{$\begin{array}{l}\text { R.I. } \\
\text { and } \\
\text { biref. }\end{array}$} & \multirow[b]{2}{*}{ Pleochroism } & \multicolumn{2}{|c|}{ Luminescence $^{a}$} & \multirow[b]{2}{*}{$X$-rays } & \multirow{2}{*}{$\begin{array}{c}\text { Absorption } \\
\text { Spectrumb }^{b} \\
(4000 \AA-7000 \AA)\end{array}$} & \multirow[b]{2}{*}{ S.G. } & \multirow[b]{2}{*}{ Inclusions } \\
\hline & & $\begin{array}{c}\text { Long-wave U.V. } \\
\text { radiation }\end{array}$ & $\begin{array}{c}\text { Short-wave U.V. } \\
\text { radiation }\end{array}$ & & & & \\
\hline $\begin{array}{c}\omega=1.762 \\
\varepsilon=1.770^{c} \\
\text { and } \\
\omega=1.760 \\
\varepsilon=1.768^{\circ} \\
0.008\end{array}$ & $\begin{array}{l}\text { Moderate to } \\
\text { strong. } \\
\text { Reddish } \\
\text { purple and } \\
\text { purplish red } \\
\text { parallel to the } \\
\text { c-axis. } \\
\text { Orangy pink, } \\
\text { orangy red, } \\
\text { and pinkish } \\
\text { orange } \\
\text { perpendicular } \\
\text { to the c-axis. }\end{array}$ & $\begin{array}{l}\text { Variable: intensity } \\
\text { ranges from } \\
\text { moderate to } \\
\text { extremely strong; } \\
\text { overall fluorescent } \\
\text { color ranges from a } \\
\text { dull, chalky red to } \\
\text { orangy red. Some } \\
\text { stones exhibit small } \\
\text { zones of chalky } \\
\text { yellow. No } \\
\text { phosphorescence. }\end{array}$ & $\begin{array}{l}\text { Intensity ranges from } \\
\text { weak to strong; } \\
\text { nearly the same } \\
\text { fluorescent colors as } \\
\text { long-wave reaction, } \\
\text { with the addition of } \\
\text { chalky, slightly bluish } \\
\text { white zones observed } \\
\text { in a few stones. No } \\
\text { phosphorescence. }\end{array}$ & $\begin{array}{l}\text { Variable: some } \\
\text { areas inert, others } \\
\text { range in intensity } \\
\text { from extremely } \\
\text { weak to weak: } \\
\text { fluorescent colors } \\
\text { range from dull, } \\
\text { chaiky red to } \\
\text { orangy red. No } \\
\text { phosphorescence. }\end{array}$ & $\begin{array}{l}\text { Absorption lines } \\
\text { at } 4750,4765, \\
4685,6592,6680, \\
6928, \text { and } 6942 \AA ; \\
\text { broad absorption } \\
\text { blocking out all of } \\
\text { the violet and } \\
\text { some of the blue, } \\
\text { all of the green } \\
\text { and yellow, and a } \\
\text { small area in the } \\
\text { orange portion of } \\
\text { the visible } \\
\text { spectrum. Not } \\
\text { diagnostic. }\end{array}$ & $3.96-4.00$ & $\begin{array}{l}\text { Various forms of residual } \\
\text { unmelted flux that may } \\
\text { be angular or rounded } \\
\text { and white to } \\
\text { orange-yellow; flux } \\
\text { "fingerprints" that range } \\
\text { from flat to very wispy } \\
\text { (wispy veils), fine to } \\
\text { coarse, near colorless to } \\
\text { white, and are seen in } \\
\text { low to high relief; and } \\
\text { numerous forms of } \\
\text { growth features and color } \\
\text { zoning. "Comet tails" } \\
\text { occasionally seen. }\end{array}$ \\
\hline
\end{tabular}

a Luminescence reactions listed are for faceted stones only and may change if the manufacturer changes the amount or type of dopant added to the flux-melt mixture.

"The visible light absorption spectrum as observed through a normal "hand-held" type of gemological spectroscope.

c This variation is also observed in natural ruby. 


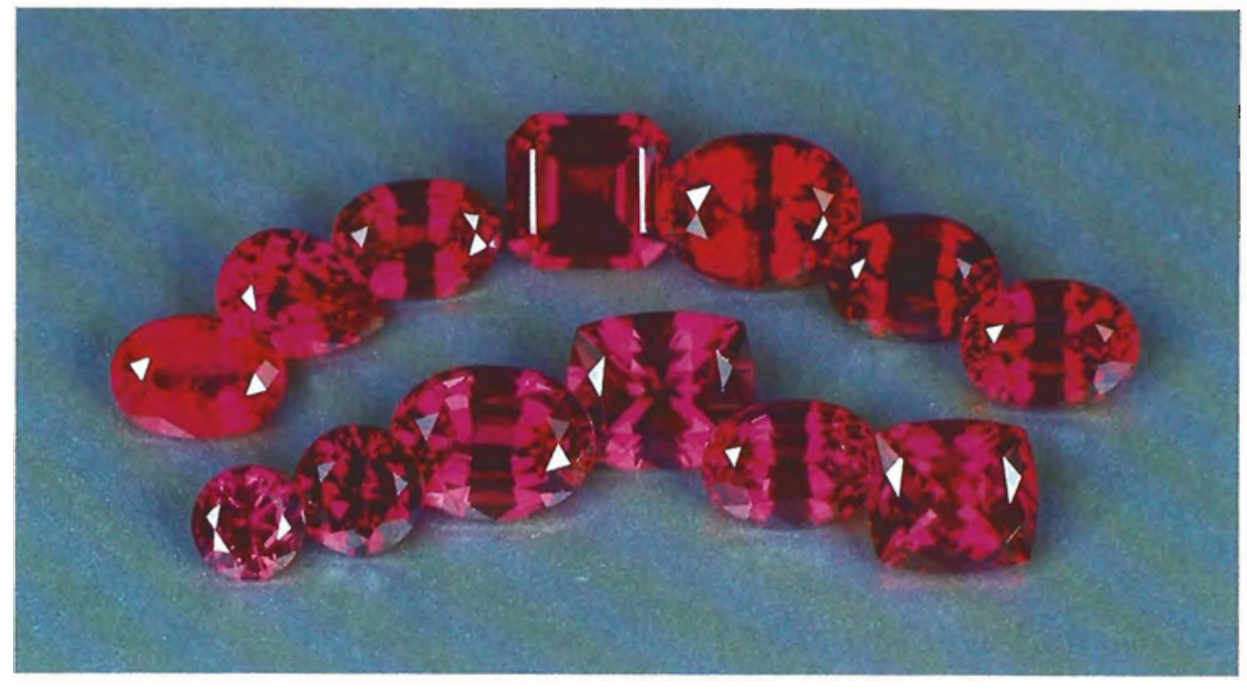

Figure 3. The Ramaura synthetic ruby is produced in several different hues, many of which are illustrated here (the stones range in weight from 0.50 to $2.00 \mathrm{ct}$ ). Photo by Michael Havstad.

hue orangy red) and pinkish orange perpendicular to the c-axis (slight overtones of brown were also observed).

Reaction to Ultraviolet Radiation. One interesting feature of the Ramaura is that the manufacturer has attempted to produce a characteristic fluorescence in the material, with the intended purpose of rendering the Ramaura synthetic ruby easily identifiable when exposed to ultraviolet radiation. It is well known that fluorescence in a gemstone may be strongly influenced by the presence of small amounts of trace-element impurities within the gem material (Nassau, 1980). The manufacturer of the Ramaura synthetic ruby has attempted to cause a fluorescence shift with the addition of minute amounts (several parts per million) of a dopant to the initial flux-melt mixture. The dopant that is currently being used is reportedly a rare-earth element (the identity of which the manufacturer wishes to remain undisclosed at this time). The dopant is absorbed in the growing crystal by replacing aluminum (Al) ions, causing the fluorescence in some areas of the rough material to shift toward orange-yellow when the synthetic ruby is exposed to ultraviolet radiation.

It is important to note at the present time that the majority of the faceted stones the author has examined to date do not show evidence of this dopant in the form of a characteristic orange-yellow fluorescence. In addition, electron microprobe analysis and energy dispersive spectrophotometry-X-ray fluorescence (EDS-XRF) analysis revealed no indication of the reportedly added dopant. If it is present, it is in concentrations below the detection limits of these very sensitive tests. The fluorescent reactions observed and the problems encountered in the doping process are discussed below.

Luminescence: Rough Material. Exposure of the Ramaura synthetic ruby crystals to long-wave ultraviolet radiation ( $3669 \AA$ ) revealed variable fluorescence reactions, ranging in intensity from moderate to very strong. The overall color of the fluorescence ranged from a dull, chalky red to an orangy red through slightly reddish orange (nearly pure orange) to a pure red that was similar in nature to the fluorescence often observed in Verneuil synthetic rubies.

Most of the crystal clusters and tabular single crystals exhibited a reas of fluorescent zoning that also varied in intensity from strong to very strong. The zoning ranged in color from a distinct sulfur yellow through a yellowish orange to a nearly pure orange. Although generally quite thin, these zoned areas also possessed a dull, chalky, translucent nature. The fluorescent zoning was most frequently observed in concentrated, thin areas parallel to the external surfaces of the crystals (figure 4). The dull, chalky fluorescent zones were observed on nearly all of the surfaces of the crystal clusters and tabular single crystals [with the $(0001)$ faces having a thicker concentration]. The only surfaces that consistently did not exhibit this fluorescent zoning were those that had grown attached to the crucible surfaces.

The fluorescent zones and their absence on surfaces that had been attached to the crucible) would indicate a change in the environment toward the end of the growth process. If the assumption that the chalky yellow and orangy yel- 


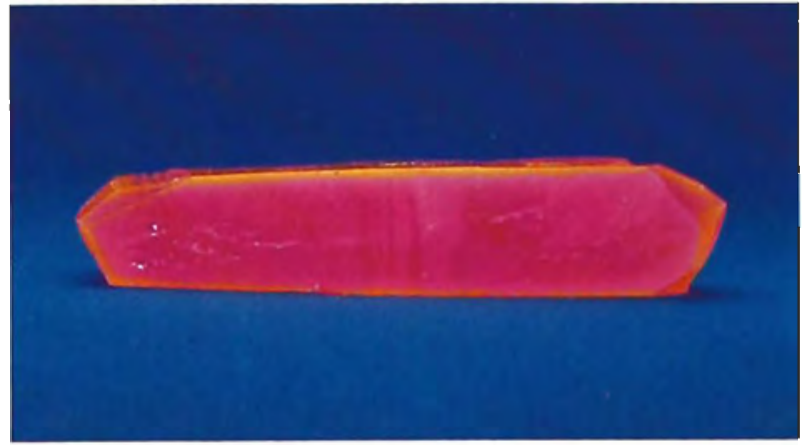

Figure 4. The strong yellow long-wave fluorescent zoning shown here paralleling the edges of this 56.14-ct Ramaura synthetic ruby crystal (the crystal surface in the foreground of the photograph grew attached to the crucible, and thus is absent of this fluorescent zoning) is reportedly induced by the addition of trace amounts of a rare-earth dopant. Photo by Michael Havstad.

low fluorescent zoning was caused by the addition of a rare-earth element is correct, the zoning is most probably caused by a dominating concentration of the dopant in the melt solution and the rapid rate of growth at the end of the growth process.

Exposure of the Ramaura synthetic ruby crystals to short-wave $(2537 \AA)$ ultraviolet radiation revealed similar reactions to those observed with long-wave ultraviolet radiation, although one of the crystal clusters examined (which the manufacturer reported had a greater amount of dopant than the material grown previously|, behaved differently. In this cluster, the dull, chalky yellow fluorescence was predominant, quenching most of the orange-red fluorescence that had been seen under long-wave ultraviolet radiation. With this one exception, the major difference of the shortwave fluorescence as compared to the long-wave reaction was the intensity, which ranged from very weak to moderate in the former.

Exposure of the Ramaura synthetic ruby crystals to X-rays also revealed a variable fluorescent reaction. Some areas were inert, while others ranged in intensity from very weak to weak. The color of the X-ray fluorescence ranged from patchy areas of dull chalky red to orangy red with a few smaller areas of dull, opaque chalky white and yellowish white. No visible phosphorescence was observed after exposure to X-rays for $10 \mathrm{sec}$ onds.
Luminescence: Faceted Stones. Exposure of the faceted Ramaura synthetic rubies to long-wave ultraviolet radiation $(3660 \AA$ ) revealed variable fluorescence, with the majority ranging in intensity from strong to extremely strong and a few exhibiting a moderate intensity. The overall color of the fluorescence in the faceted stones varied from dull chalky red to orangy red. Also seen in a few stones was an orange-red to pure red fluorescence that was very similar in nature to that often observed in Verneuil synthetic rubies, in that it was very vibrant and transparent in contrast to the dull, chalky (translucent, nearly opaque) nature of the fluorescence observed in many fluxgrown synthetic rubies.

As would be expected, most of the thin yellow fluorescent zones were removed during the cutting process. Some of the faceted Ramaura synthetic rubies, however, exhibited small areas of dull, chalky yellow fluorescent zoning near the outer edges of the stone (frequently observed at the culet and girdle edges). There was not a sharp deliniation between the dull, chalky yellow fluorescent zones and the red to orangy red fluorescence; rather a subtle blending of the two fluorescent colors was most commonly observed. If the property of fluorescence is hastily examined, the chalky yellow fluorescent zones could be overlooked, if it is carefully examined, however, these zones are readily apparent and provide the gemologist with a good indication of the synthetic origin of the material.

Exposure of the faceted Ramaura synthetic rubies to short-wave ultraviolet radiation 12537 $\AA$ ) also revealed a variable fluorescence. The intensity ranged from weak to strong, with the majority of the stones exhibiting a moderate intensity. The zoning and color of the short-wave fluorescence was similar to that of the long-wave fluorescence. The faceted stones exhibited a dull red to orangy red fluorescence. Of the few stones that exhibited a pure red fluorescence similar to that often observed in Verneuil synthetic rubies when exposed to long-wave ultraviolet radiation, only three showed the same overall reaction to short-wave ultraviolet radiation. The remainder in this group exhibited very easily visible zones of strong chalky, slightly bluish white zoning, confined either to the table or to areas near the culet of the faceted stone. This fluorescent zoning also blended gradually into the overall red to orangy red areas. The same stones that exhibited the 
chalky yellow zones when exposed to long-wave ultraviolet radiation also showed nearly the same reaction to short-wave ultraviolet. The major difference was the intensity of the yellow zoning, which was stronger with short-wave than with long-wave.

Exposure of the faceted Ramaura synthetic rubies to $\mathrm{X}$-rays revealed an extremely weak to weak fluorescence, with a few stones exhibiting a fluorescence of moderate intensity. The color of the X-ray fluorescence ranged from a dull, chalky red to an orangy red. In some of the faceted material, the centers of the stones showed a nearly inert reaction to X-rays, with only the edges of crowns fluorescing very weakly. This was particularly noticeable when the faceted stones were placed table down. The same reaction is also observed in many other synthetic rubies as well as in natural rubies. No visible phosphorescence was observed in the faceted stones after X-ray excitation for 10 seconds.

Although at this time the reported addition of a dopant to produce a characteristic fluorescence in the Ramaura synthetic ruby cannot always be considered conclusive in identifying this new synthetic ruby, the distributor reports that the manufacturer is continuing experimentation in this area (Peter Flusser, personal communication, 19831 .

Several conclusions can presently be drawn from the reactions to ultraviolet radiation of the faceted Ramaura synthetic ruby:

- The intensity of the overall fluorescence is ambiguous, in that it overlaps with the fluorescent reactions of some natural rubies, with the exception that some natural rubies reveal an inert reaction, while all of the Ramaura synthetic rubies exhibited some degree of fluorescence.

- If the chalky yellow and chalky, slightly bluish white fluorescent zones are observed with longwave and/or short-wave ultraviolet radiation, the gemologist has a very good indicator of the synthetic origin of the material.

- It is extremely important to note, however, that if the chalky fluorescent zoning is not present, because of its initial absence in the rough material or its removal during the cutting process, nothing conclusive concerning the synthetic or natural origin of the material in question can be determined on the basis of its luminescence.
Transparency to Short-wave Ultraviolet Radiation. Synthetic ruby in general transmits ultraviolet radiation more readily than does natural ruby. One method of determining the degree of transparency to short-wave ultraviolet radiation is to record it on photographic print paper. This method is often referred to as the short-wave ultraviolet transparency test.

For this test, seven faceted Ramaura synthetic rubies were selected, two that reportedly were undoped and five that reportedly contained the added dopant. The latter five stones were chosen on the basis of their wide range of hues and varying degrees of clarity. For comparison purposes, a selection of synthetic rubies of different manufacture and several natural rubies from various geographical localities were also included.

The subject stones were immersed table down in water over the emulsion side of a piece of contact-positive printing paper in a darkroom. The short-wave ultraviolet unit was positioned 18 inches above the vessel and the paper was exposed for approximately one-half second. Developing and fixing were done in the usual manner. The results are shown in figure 5 (top row $=$ natural rubies; bottom row $=$ Ramaura synthetic rubies; middle row $=$ synthetic rubies of various manufacturers). At this point, it would appear that there is not sufficient difference in transparency between some natural stones and some synthetics to use this test as the only basis for identification.

Spectral Examinations. The visible light absorption spectra of several faceted Ramaura synthetic rubies were examined with a GEM spectroscope unit. The observed spectra appeared to be essentially the same as the absorption spectrum described by Liddicoat (1977) for natural and synthetic ruby, as shown in figure 6. For more detailed examinations, the previously mentioned group of seven Ramaura rubies (specifically chosen on the basis of whether or not they were doped and the range of hues and clarity represented) were subjected to the following tests: (I) ultraviolet and visible light spectrophotometry, (2) infrared spectrophotometry, (3) fluorescence spectrophotometry, and (4) energy dispersive spectrophotometry-X-ray fluorescence (EDSXRF) analysis.

Ultraviolet and Visible Light Spectrophotometry. Examination of the ultraviolet and visible 


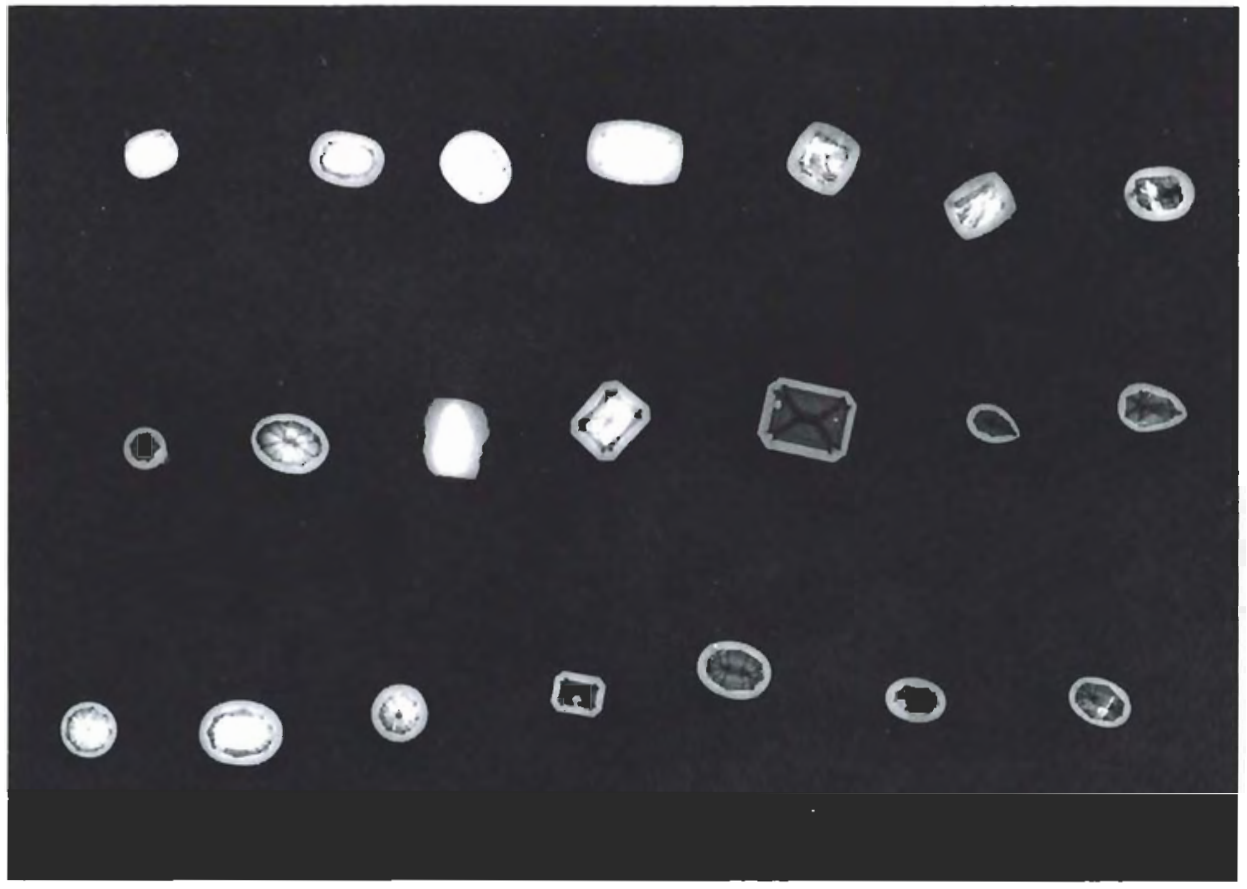

Figure 5. The results of a short-wave ultraviolet transparency test performed on a carefully selected group of natural and synthetic rubies. Top row, natural rubies (left to right): 1,2 , and 3 are from Southeast $A$ sia; 4,5 , and 6 are from East $A$ frica; and 7 is from Burma. Middle row, synthetic rubies (left to right): 1 and 2 are Kashan, 3 is Knischka, 4 and 5 are Verneuil process (manufacturer unknown), 6 is Inamori, and 7 is Chatham. Bottom row, Ramaura synthetic rubies (left to right): reportedly 1 and 2 are un doped and 3 though 7 are doped with trace amounts of a rare-earth element.

light absorption spectra of the seven faceted Ramaura synthetic rubies was conducted on a Pye Unicam, SP8-100 UV-VIS spectrophotometer by G. Bosshart, laboratory director at the Swiss Foundation for the Research of Gemstones, Zurich, Switzerland (see figure 7).

A procedure has been described by Bosshart (1982) which evaluates the differential transmission behavior in the ultraviolet region of natural and synthetic rubies. This method is a refined version of the short-wave ultraviolet transparency test discussed above (see figure 5).

Using this method to examine many natural rubies from various geographical localities and synthetic rubies of different manufacture, Bosshart was able to show many differences in ultraviolet transmission. The "population" dis-

Figure 6. Drawing of absorption spectrum for Ramaura synthetic ruby, as observed on a direct-vision spectroscope (in angstroms) at room temperature.

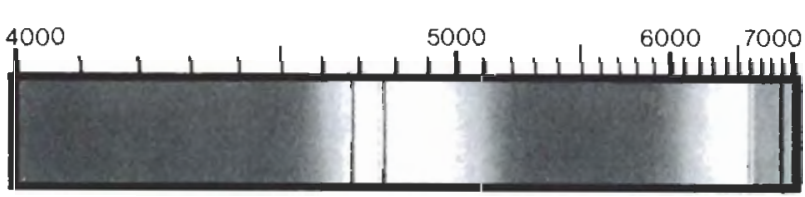

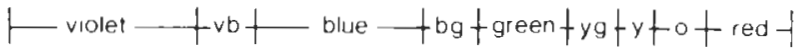

tribution of natural and synthetic rubies as determined by Bosshart's testing is reproduced in figure 8 . His testing of the seven selected Ramaura synthetic rubies revealed interesting results. Five of the seven fell within or near the natural population (depending on the optic axis orientation); one stone fell barely within a synthetic population, while the other was near it. The latter two stones were both reportedly undoped.

Infrared Spectrophotometry. B. Suhner, of Herisau, Switzerland, used a beam condenser to examine the infrared spectra of three of the seven selected samples. All three stones absorbed heavily below $1500 \mathrm{~cm}^{-1}$. The only safe statement that can be made concerning the infrared examination is that the Ramaura synthetic rubies, like other natural and synthetic corundums, are free of $\mathrm{H}_{2} \mathrm{O}$ and $\mathrm{OH}$.

Fluorescence Spectrophotometry. The fluorescence spectra were recorded on a Perkin-Elmer fluorescence spectrophotometer 650-10, also by B. Suhner. Although Suhner recorded extreme variability in the relative excitation-peak intensities, qualitatively he found them to be identical: the spectra showed the same number of peaks in the same wavelength positions except for a band at $318 \mathrm{~nm}$ in one of the samples. The excitation peak at $268 \mathrm{~nm}$, which has been observed in other synthetic rubies as well as in many natural rubies from Burma and Sri Lanka, but is absent in most 


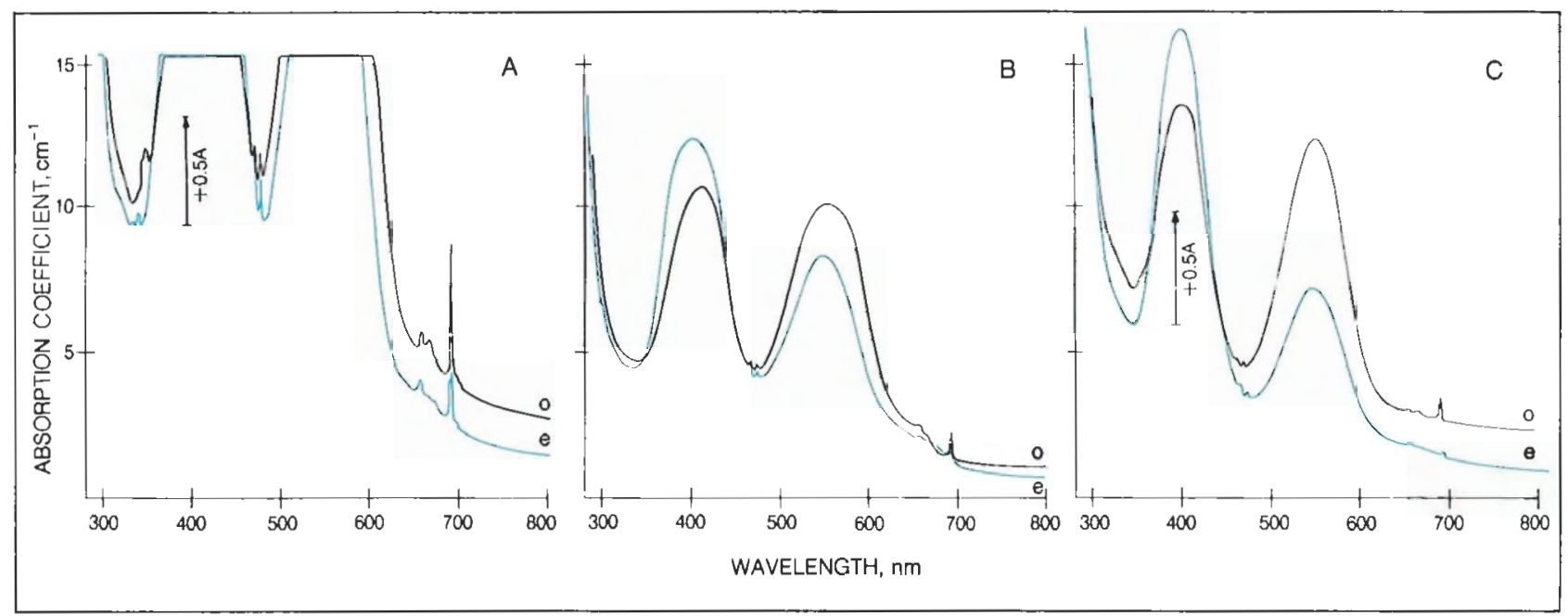

Figure 7. Polarized ultraviolet-visible absorption spectra of three faceted Ramaura synthetic rubies recorded at ambient temperature. Vibration o (of the ordinary ray) perpendicular to the optic axis (black), vibration e (of the extraordinary ray) parallel to the optic axis (blue). The absorption coefficient is approximate. Profiles at $+0.5 \mathrm{~A}$ (absorbance unit) level above absolute absorption minimum in the ultraviolet. Spectra particularities are as follows: (A) Peaks at approximately $405 \mathrm{~nm}$ and 550 $n m$ well off-scale due to high chromium dotation producing a dark red color. This 0.84-ct stone was reportedly undoped. (B) Low chromium dotation leading to a pale violetish red color. (Peak heights reduced by sample-related straylight influence, except for the e-peak at about $548 \mathrm{~nm}$.) This 0.92-carat stone was reportedly doped. (C) Low chromium and iron dotation giving a slightly violetish red color. Note: The absorption maxima and minima below $460 \mathrm{~nm}$ are influenced by iron content alone. No straylight effects: proper peak height ratios for ruby. Also note that absorption in the blue region (480 $\mathrm{nm}$ ) is lower than in the ultraviolet ( $350 \mathrm{~nm})$, contrary to stone $A$. This 0.94 -carat stone was reportedly doped. Spectra and legend provided by G. Bosshart.

other natural rubies (Bosshart, 1982), was not present in the Ramaura synthetic rubies that were examined. Any details related to the re- ported rare-earth dopant were also not observed. Low-temperature fluorescence spectra may yield more specific information.

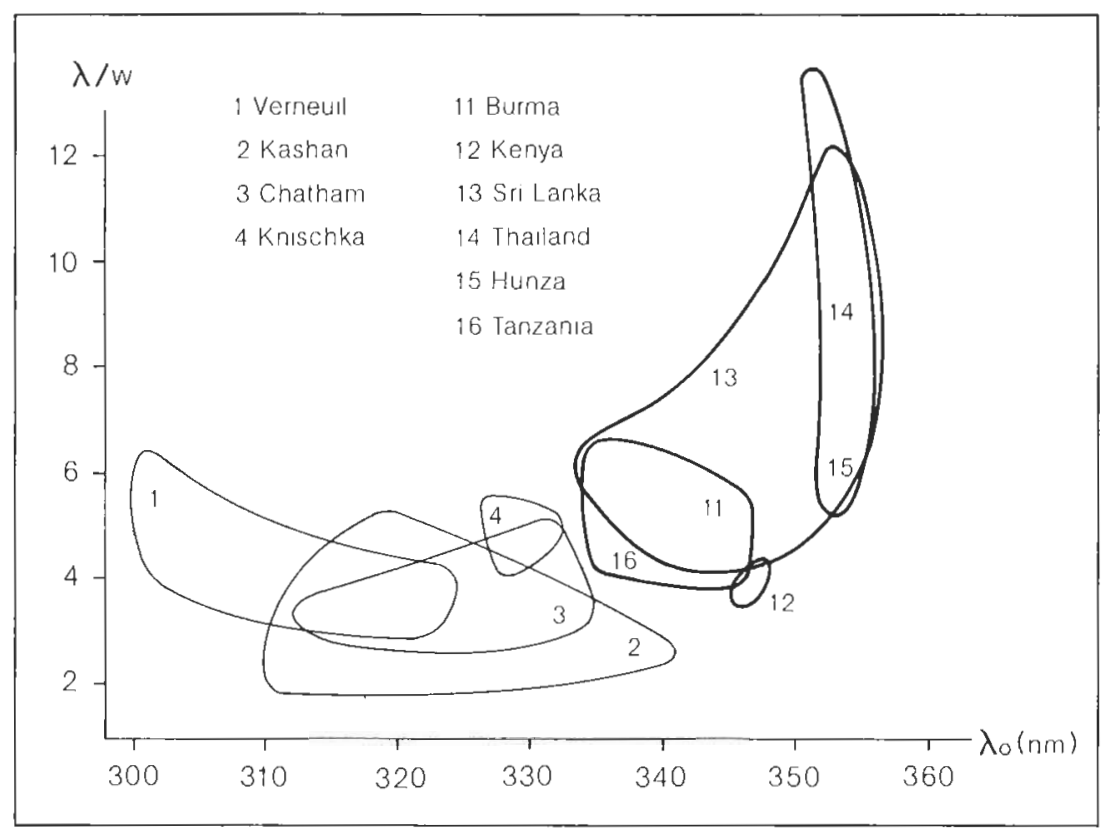

Figure 8. "Population" distribution of natural rubies (top right) and synthetic rubies (bottom left), determined from the ultraviolet absorption minima (vibrational component $e>0$ ); after G. Bosshart. Seven specifically chosen Ramaura synthetic rubies were tested with this method: the five reportedly doped stones fell well within the natural population areas; the remaining two reportedly undoped Ramaura synthetic rubies were plotted very near the synthetic population areas. 
EDS-XRF Analysis. The seven selected Ramaura synthetic rubies were examined using EDS-XRF analysis by Dr. H. A. Hänni of the Swiss Foundation for the Research of Gemstones and Dr. W. B. Stern of the Geochemical Laboratories, Institute for Mineralogy and Petrography, Basel, Switzerland. For a detailed description of this method of analysis, the reader is referred to Stern and Hänni (1982). The analyses revealed extremely variable results on the seven stones. Trace-element contents and concentrations varied considerably among the seven samples.

In a recent paper (1982), Hänni and Stern reported on their investigation of gallium $(\mathrm{Ga})$ as a trace element in a small selection of natural and synthetic corundums. All of the natural corundums contained $\mathrm{Ga}$ concentrations in excess of $200 \mathrm{ppm}$. In the synthetic corundums examined in that study, Ga could not be detected.

Their initial examinations of the seven Ramaura synthetic rubies indicated the presence of $\mathrm{Ga}$ in concentrations near the detection limit of EDS-XRF analysis in six of the seven stones. The remaining stone showed greater concentrations of Ga.

Because of the presence of $\mathrm{Ga}$ in the seven Ramaura synthetic rubies tested, the occurrence of this element in trace amounts should not be considered a conclusive indicator of natural origin at this time. In fact, from the above discussion, it is evident that none of these spectral examination techniques currently offers a definitive means of identifying the Ramaura synthetic ruby from its natural counterpart.

Specific Gravity. The specific gravity values for the Ramaura synthetic ruby were determined by means of the hydrostatic technique, using a Voland diamond balance equipped with the necessary specific gravity attachments. The synthetic material showed slight variations in density, from 3.96 to 4.00 .

Inclusions. With the exception of the luminescent reactions of a small percentage of the faceted stones tested by the author, all of the previously discussed gemological properties of the Ramaura synthetic ruby overlap to some extent with those of its natural counterpart. Therefore, at the present time the most important means of distinguishing the new Ramaura synthetic ruby from natural ruby is provided by the presence of characteristic inclusions.
Because of controlled environments for crystal growth, synthetic rubies in general exhibit a somewhat limited variety of inclusions in contrast to the seemingly limitless multiplicity of inclusions found in natural rubies. The current growth process of the Ramaura synthetic ruby produces material that contains an even narrower variety of internal characteristics than is frequently observed in other commercially available faceted flux-grown synthetic rubies, such as the Chatham and Kashan products.

Despite the small number of basic inclusion types found in the Ramaura synthetic ruby, most of the internal characteristics can be considered diagnostic of synthesis to the experienced gemologist. To date, the following types of inclusions have been commonly observed by the author in faceted pieces of Ramaura synthetic ruby: various forms of flux, fractures and healed fractures, and numerous forms of growth features and color zoning. In a small number of the stones examined, "comet tail" inclusions were observed.

Platinum was not observed as an inclusion in any of the 160 faceted Ramaura synthetic rubies examined. However, one very small, thin metallic flake, presumably platinum, was seen positioned very near the surface of one of the Ramaura crystals. Platinum crucibles reportedly are used in the Ramaura growth process. However, the type of flux currently used by the manufacturer does not usually attack the platinum crucible (Peter Flusser, personal communication, 19831; thus, platinum does not commonly occur as an inclusion, and at this time it should not be considered as one that is characteristic of the Ramaura synthetic ruby.

The faceted stones examined ranged from those with prominent and easily identifiable flux inclusions, color zoning, growth features, and fractures, to those that appeared to be flawless. The seemingly flawless stones, however, revealed distinctive subtle growth features when they were carefully examined with the gemological microscope.

Flux. Typically observed in other flux-grown synthetic rubies are various forms of residual unmelted flux, which commonly range from transparent and near colorless to opaque and white. Many of the new Ramaura synthetic rubies also contain several forms of flux inclusions. These flux inclusions are distinctive from those ob- 


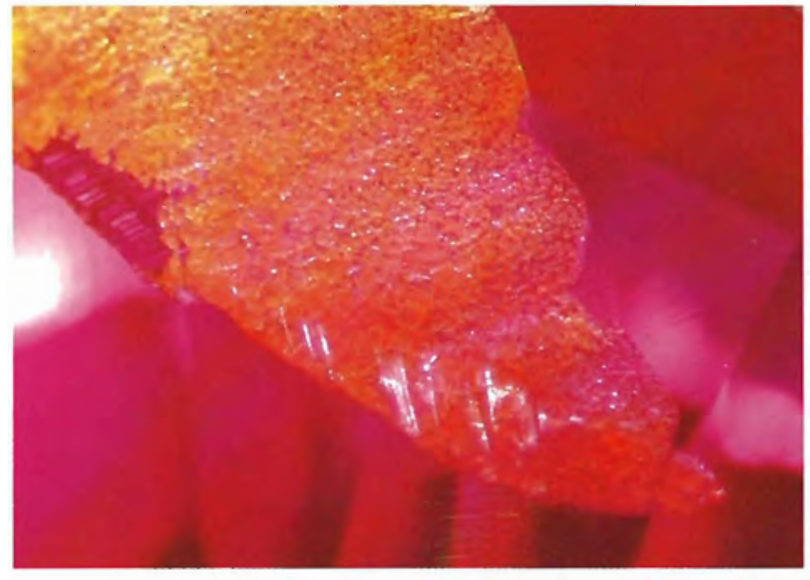

Figure 9. A distinctive orange to yellow color characterizes many of the flux globules and flux-filled voids in Ramaura synthetic rubies. The "crackled" appearance seen here is also quite typical of the Ramaura growth process. These flux inclusions can range from very rounded to very angular with straight, parallel steps. Dark-field and oblique illumination, magnified $35 \times$.

served in other flux rubies in that they frequently appear orange-yellow, although they may also range from near colorless to white.

The flux typically observed in the Ramaura synthetic rubies ranged in size from minute, nondescript particles to very large, "drippy"-appearing globules to primarily flux-filled negative crystals. These can be very angular with straight, parallel steps, or they may be very rounded in appearance (see figure 9).

Although these flux inclusions are frequently orange-yellow, opaque, and seen in very high relief, they may also exhibit portions that range from near colorless to white and semitransparent to opaque, observed in low to very high relief with highly reflective surfaces (see figure 10). They exhibit several forms that may take on a "rib-like" arrangement or have a "rod-like" appearance and can also be either angular or rounded. They may be observed singularly, randomly interspersed among one another, or in somewhat parallel clusters or groups (see figure 11).

Many of the predominantly orange-yellow flux inclusions are observed as partially filled flux channels or voids. This type of inclusion forms when molten flux is trapped within the rapidly growing crystal and later crystallizes or partially crystallizes as the synthetic ruby crystal cools. This often results in a "crackled" appearance \{again, see figures 9 and 11). These inclusions may

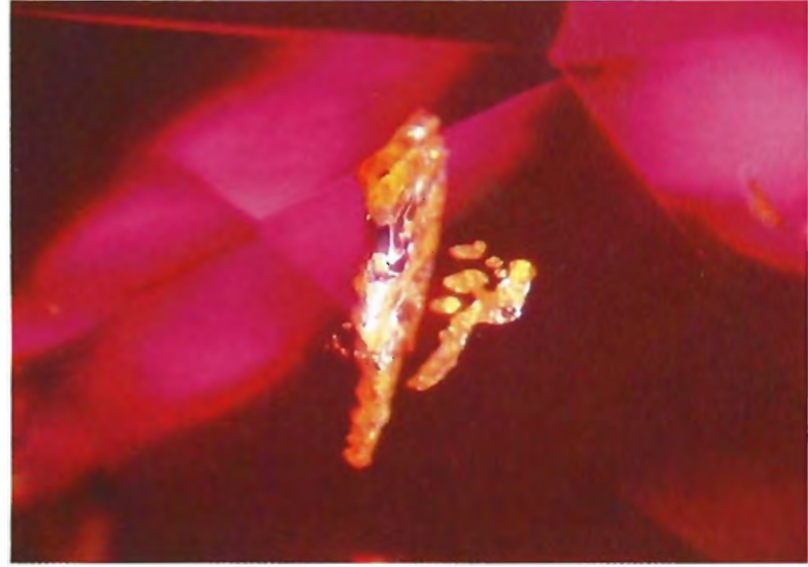

Figure 10. Flux-filled voids exhibiting portions that range from near colorless and highly reflective through white to orange-yellow. Dark-field illumination, magnified $55 \times$.

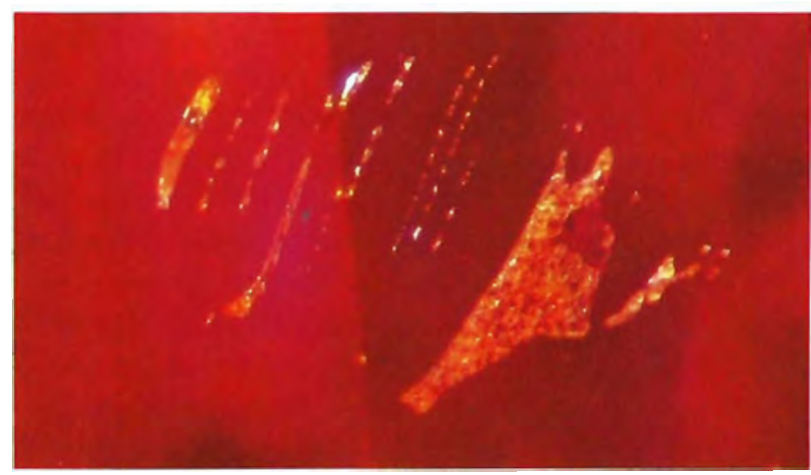

Figure 11. Somewhat parallel groups of voids filled with orange-yellow flux. Some of these inclusions exhibit a two-phase-like appearance; however, they are most probably solid in nature. Dark-field and oblique illumination, magnified $45 \times$.

also exhibit a two-phase-like appearance; however, they are probably not, by definition, twophase inclusions but, rather, are completely solid in nature (see figure 11).

Also observed, though rarely, were flux-filled voids that ranged from mostly white to those with small portions of highly reflective, near-colorless areas. These were both rounded and angular in appearance and were interspersed among one another in groups or clusters.

Some of the Ramaura synthetic rubies frequently revealed a residual unmelted flux in the form of "fingerprints" that ranged from transparent to opaque, and near colorless to white, in low to high relief. None of the flux fingerprints was orange-yellow. These fingerprint patterns also 


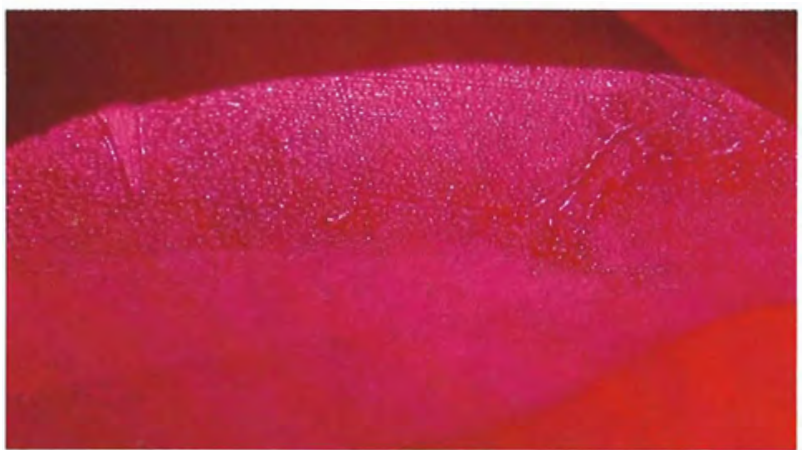

Figure 12. Healing fracture filled with white flux forming a flux "fingerprint" composed of a combination of tiny, closely arranged droplets and more loosely arranged mesh-like patterns. Dark-field and oblique illumination, magnified $32 \times$

varied from very tightly arranged drops or grains, which formed mesh-like patterns that remarkably duplicated the appearance of natural fingerprints, to loosely arranged, wide, flat mesh- or lace-like patterns that were easily identifiable as flux. These forms were also observed together in one fingerprint pattern (see figure 12). Both types of flux fingerprints were observed to range from flat to very curved forms, often referred to as wispy veils, that sometimes intersected in several planes (see figure 13) or radiated outward from a central point (see figure 14). As with the previously discussed orange-yellow flux inclusions, the individual grains or drops that form the fingerprint patterns may give the appearance of minute two-phase-like inclusions, but it is probable that these, too, are completely solid. The orange-yellow flux inclusions and the white flux fingerprints were occasionally seen in association with one another (see figure 15).

Fractures. Many of the Ramaura synthetic rubies contained fractures and healed fractures, which were often iridescent and reflective at certain viewing angles when examined with either dark-field or oblique illumination. Many of these fractures and healed fractures were also very similar in appearance to the epigenetic staining that is observed in many natural minerals. At the present time, these fractures cannot be considered diagnostic of synthesis, since they are often remarkably similar to those seen in natural rubies.

Growth Features and Color Zoning. Observed in all the faceted Ramaura synthetic rubies examined were various forms of growth features and

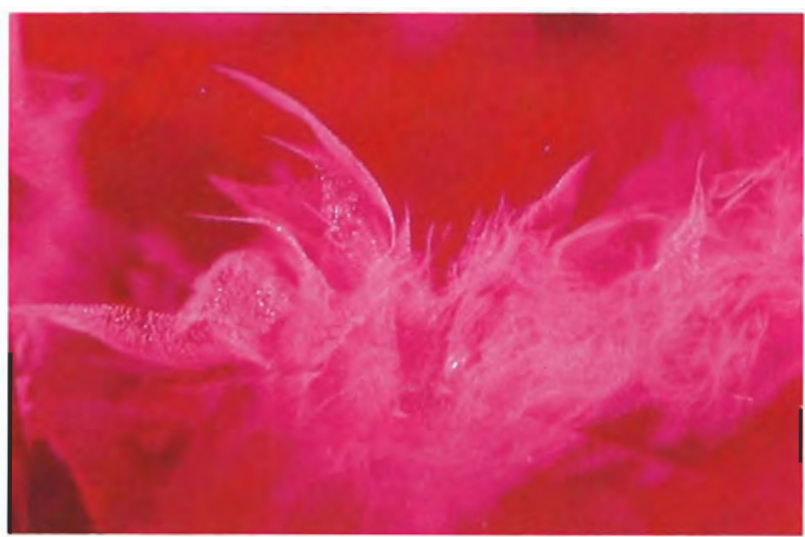

Figure 13. White, wispy veils, fine to moderate in texture, betray the synthetic origin of this Ramaura synthetic ruby. Dark-field and oblique illumination, magnified $40 \times$

color zoning. The term growth feature is used here to refer to other irregularities in the internal appearance of the material that are not inclusions in the narrow sense of the word. They include optically detectable inhomogeneities such as twinning, parting, and structural defects, and growth phenomena such as "phantoms." The growth features and color zoning were extremely variable in appearance. They were observed in one or a combination of the following forms: straight, parallel, and uniform; curved; angular; hexagonal; very swirled and irregular, resembling "phantom" or "scotch and water" graining in diamonds; or intersecting in various planes (see figures 16 through 26). Some of these growth features were reminiscent of those often observed in many Chatham (Fryer et al., 1981) and Kashan synthetic rubies (Kane, 1979, Gübelin, 1983). The growth features and color zoning ranged from being very easily seen with the unaided eye to being difficult to locate under magnification even when several different lighting techniques were used. Although many of the faceted stones (some as large as $5 \mathrm{ct}$ ) contained no flux inclusions or were such that the flux could be easily removed with recutting, they all contained some form of growth features or color zoning. In some stones, the growth features or color zoning were barely perceptible; in others they were easily seen throughout the entire stone.

As is the case with most natural or synthetic materials, the nature of these growth features can be very elusive. When a faceted stone is held in a certain manner and is viewed at specific angles, the growth features may be very evident. At other positions and viewing angles, they may totally 


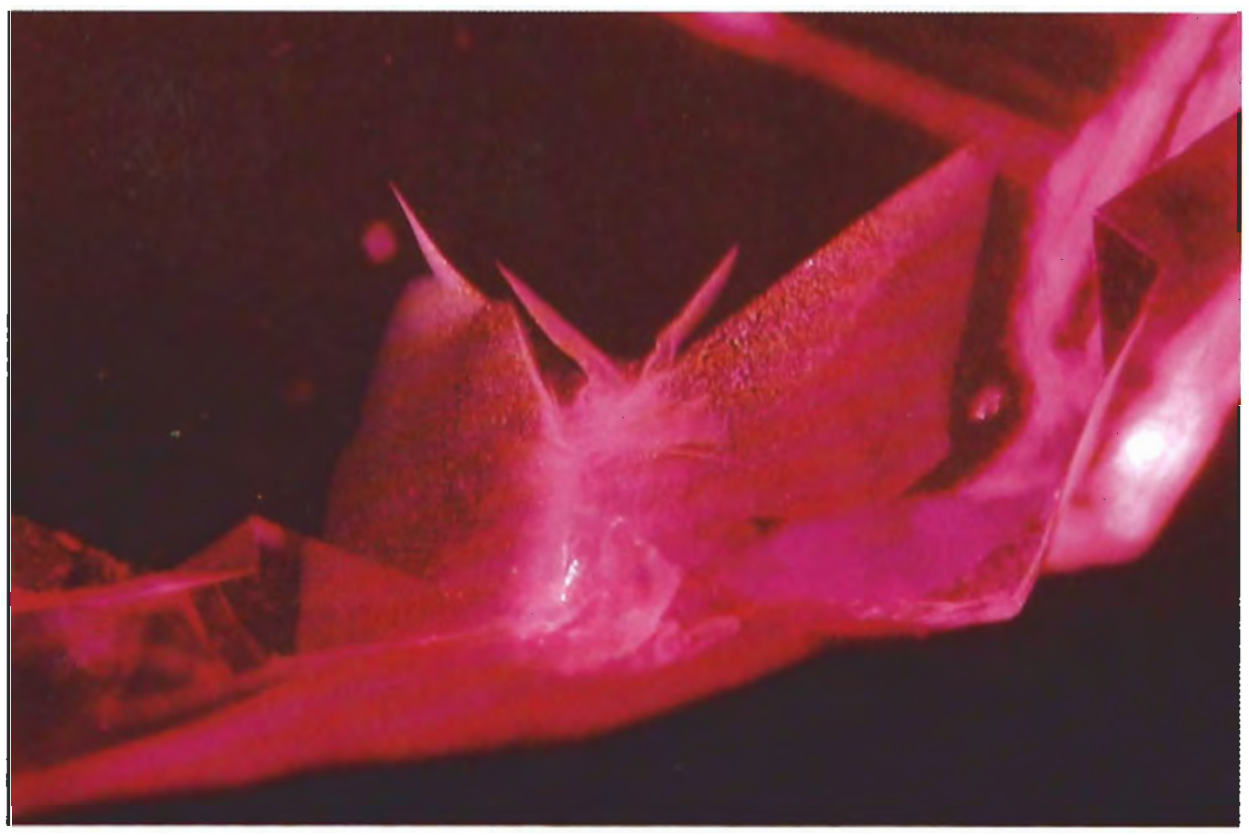

Figure 14. White flux "fingerprints" radiating outward from a central point in a Ramaura synthetic ruby. Dark-field and oblique illumination, magnified $25 x$.

disappear from view (see figure 16). Certain growth features may be seen only through the pavilion and not through the crown or vice versa; others may be readily apparent when the stone is held table to culet, but will not be seen at all when it is held girdle to girdle.

Likewise, the appearance of an inclusion can be changed dramatically by employing different types of illumination. For routine examination, dark-field illumination usually provides the most effective means of lighting the interior of a gemstone. However, the most effective for examining color zones and growth features in synthetic and natural rubies are oblique, transmitted, and diffused illumination, as well as shadowing loften used in combination with one another or with dark-field). The reader is referred to Koivula (1981, 1982a, and 1982b) for a detailed discussion of oblique and transmitted illumination and the shadowing technique. Diffused illumination is produced by placing some type of diffuser (e.g., a tissue) over dark-field illumination or transmitted light. Similar to, but softer than, transmitted light, the results of diffused illumination approximate those obtained with immersion techniques, which are often far more troublesome.

Because many Ramaura synthetic rubies exhibit only growth features and color zones, it is extremely important to be familiar with these inclusions and how to locate them. Although some features are similar to those observed in other flux-grown synthetic rubies, others will un- doubtedly be new to many gemologists. Among the potentially most confusing are the uniform, nearly straight parallel growth bands (see figures 16 and 17) which can also be observed forming an angle (see figure 18). These growth features are

Figure 15. Orange-yellow flux globules interspersed among white, wispy flux "fingerprints" in a Ramaura synthetic ruby. Dark-field and oblique illumination, magnified $20 \times$.

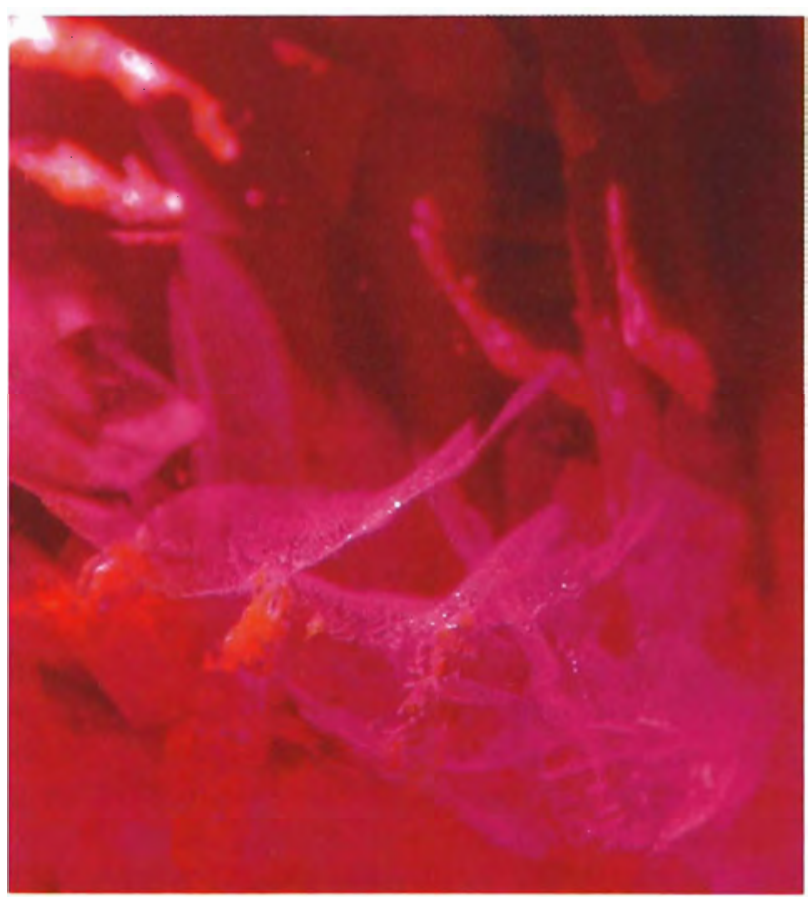



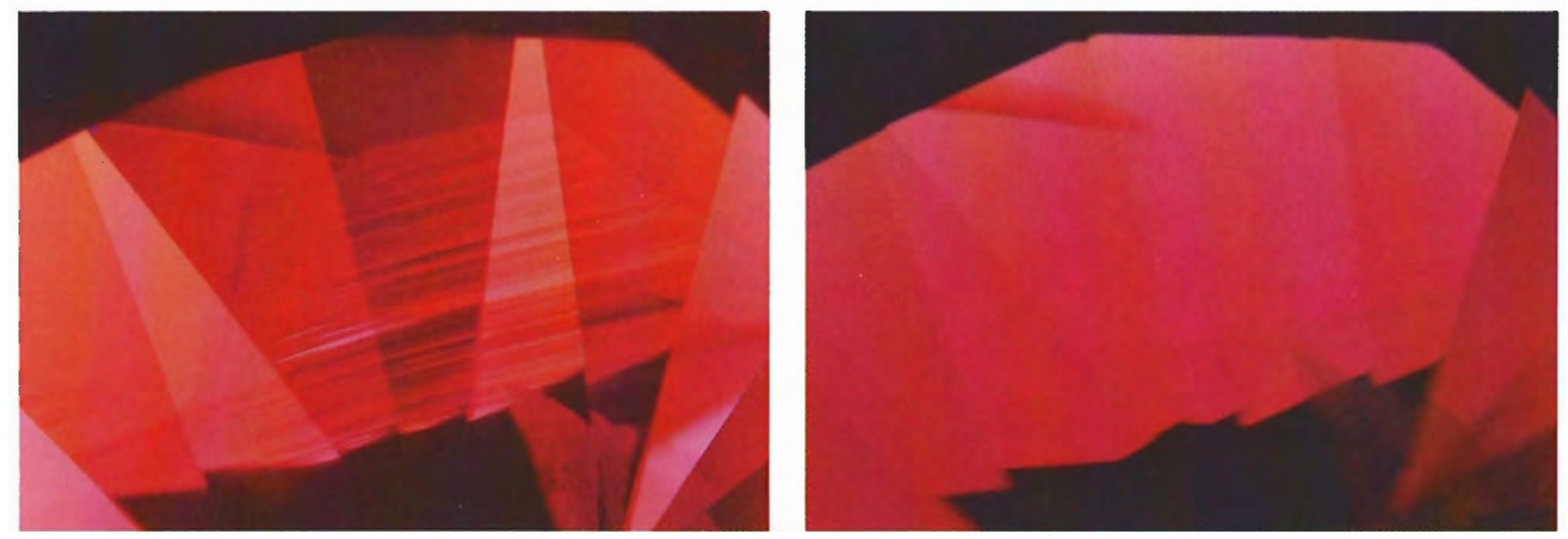

Figure 16. These two photomicrographs of a Ramaura synthetic ruby fully illustrate how dramatically the appearance of some growth features can change with slight movements of the stone. On the left are seen prominently visible, nearly straight parallel growth bands. On the right, the stone has been tilted very slightly, causing nearly all of the growth features to disappear from view. Dark-field illumination, magnified $20 \times$

easily distinguishable from the polysynthetic twin-lamellae that can occur in natural ruby; therefore, they are diagnostic of synthesis. The planes of the twin-lamellae, or laminated twinning, extend deep into the interior, often completely through the natural ruby, in contrast to some of the synthetic growth bands which disappear from view when the microscope objective is raised or lowered. In this respect, the nearly straight, parallel growth bands react very comparably to the familiar curved striae that are typical of Verneuil synthetic rubies. This particular reaction and type of inclusion is also observed frequently in Kashan synthetic rubies (Gübelin, 1983).

Various types of angular growth zoning are also observed in the Ramaura synthetic ruby. They may be similar in nature to those growth features previously discussed or may extend deep into the stone and closely resemble laminated twinning (figure 19). This angular zoning often seems confusing to gemologists; however, it can be considered diagnostic of the Ramaura if the differences from natural growth features are understood.

Although angular zoning planes that do not intersect one another (V-shaped) are quite common in some varieties of corundum, especially blue sapphire, they have not been observed by the author in natural transparent ruby. Only laminated twinning planes that intersect one another at an angle or rhombohedral twin lamination even approach this type of zoning. Strongly defined "hexagonal" or angular growth zoning that does not intersect has thus far been observed only in natural rubies that are translucent or opaque; usually they are asteriated.

The angular or "hexagonal" zoning in synthetic rubies may appear to meet in sharply defined angles or, more commonly, at slightly rounded or blurred junctions, depending on the viewing angle and type of illumination used. This characteristic provides the gemologist with an easily identifiable and diagnostic inclusion.

Single, straight growth planes that extend deep into the interior of the stone are sometimes observed in the Ramaura synthetic ruby. If isolated, these growth planes are nearly indistinguishable from laminated twinning in natural rubies. However, they are commonly associated with curved or irregular growth features, such as is shown in figure 20 , and the synthetic origin of the stone is betrayed.

Many other growth features and color zones that may be curved, swirled, and irregular are also characteristic of the Ramaura synthetic ruby (see figures 21 through 28). Very swirled and irregular growth features resembling "phantom" graining in diamonds or the "heat-wave" effect seen in many gemstones are shown in figure 21 . These should not be confused with the very distinctive "treacle" color zoning seen in many natural Burmese rubies.

"Comet Tails." Also observed in a few of the Ramaura synthetic rubies examined were fine, straight lines and V-shaped arrangements of stringers composed of minute, white, particles 
(presumably undissolved flux). These features, often referred to as "comet tails," also occur in other synthetic rubies, such as those produced by Kashan (Kane, 1979; referred to as "hairpins" and "comets" in Gübelin, 19831, as well as in many natural gemstones and, very rarely, in natural rubies. In natural gemstones, they almost always are seen trailing behind an included crystal and are the result of directional growth disturbance caused by the included crystal. In synthetic rubies, comet tails are most commonly seen isolated, that is, not trailing behind an inclusion. In one of the Ramaura synthetic rubies, however, several comet tails were observed trailing a flux fingerprint. Because of their distinctive appear-

Figure 17. This Ramaura synthetic ruby displayed unusual growth features: at some viewing angles the nearly straight, parallel growth bands appeared similar to the left view in figure 16; at others, a complete iridescence was exhibited; and at still others, as is shown here, both features were observed. In this view, the very slight differences in angle between facets causes the growth features to be iridescent in one and not in the others. Dark-field illumination, mag. nified $50 \times$

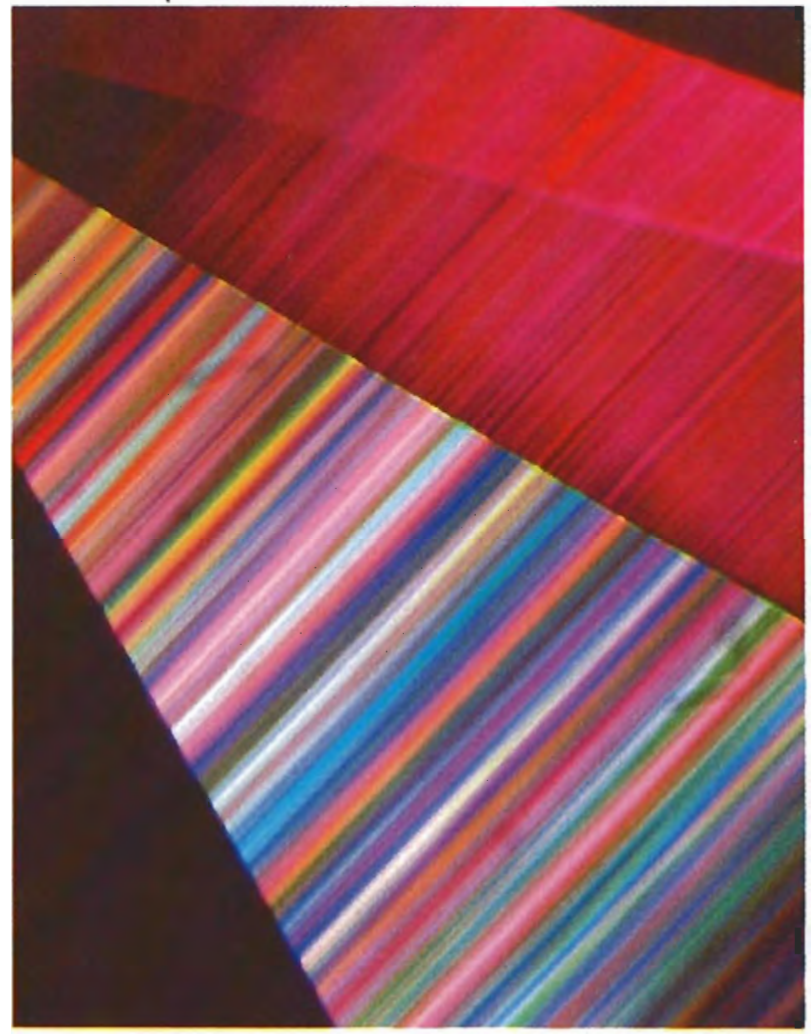

ance and the rare occurrence of this type of inclusion in natural rubies, comet tails provide an excellent indication of synthesis in rubies.

As is evident from the above discussion, in the separation of synthetic rubies from their natural counterpart it is of equal importance to examine the other side of the coin: the characteristics of natural rubies. Unlike the somewhat limited nature of inclusions found in synthetic rubies, natural rubies provide a seemingly endless variety of inclusions. The more of these natural inclusions the gemologist is familiar with, the easier the identification of the material will be.

\section{CONCLUSION}

The new Ramaura synthetic ruby has many characteristics that closely correspond to those of natural ruby. With the exception of the luminescence reactions of a small percentage of the faceted stones tested by the author and most of the internal characteristics, the gemological properties of the Ramaura synthetic ruby overlap, at least to some extent, with those of its natural counterpart. Therefore, at this time the most important means of distinguishing the new Ramaura synthetic ruby from natural ruby is provided by the inclusions present. To date, the following types of inclusions have been commonly

Figure 18. With the built-in iris diaphragm on the Gemolite microscope stage partially closed (over dark-field illumination) to create a shadowing effect in this Ramaura synthetic ruby, several different forms of growth features become evident. Particularly notable is the straight growth band that forms an angle in the center of this photomicrograph. Magnified $30 \times$

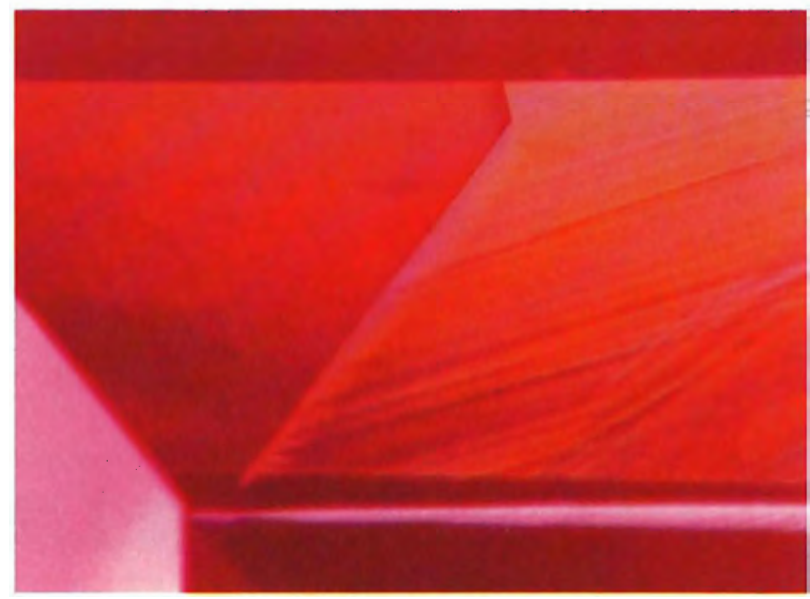


Figure 19. V-shaped or "hexagonal" growth band in association with curved growth features in a $\mathrm{Ra}$ maura synthetic ruby. Dark-field illumination and shadowing, magnified $25 x$.

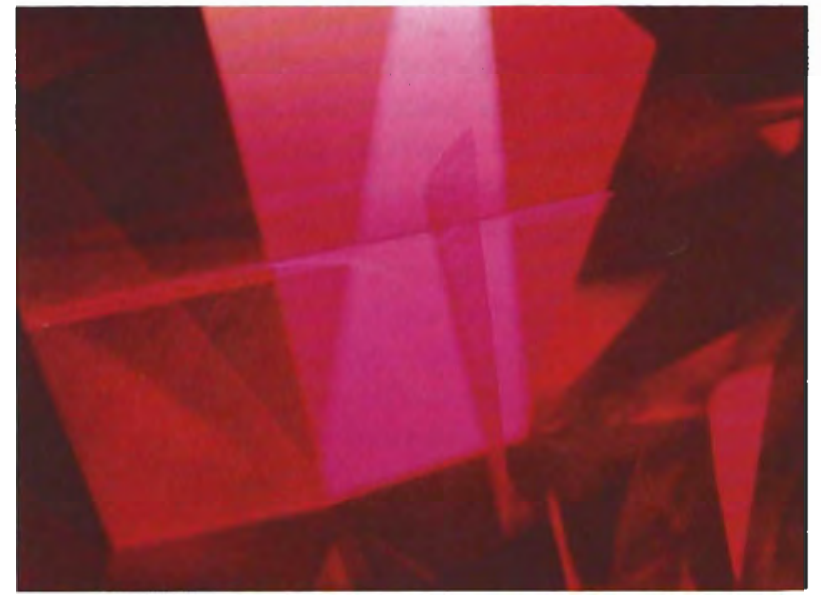

Figure 20. The straight growth plane that extends in to the interior of this Ramaura synthetic ruby is intersected by a flux "fingerprint" and a small curved growth feature. Dark-field illumination, magnified $20 \times$.

Figure 21. The shadowing technique accentuates the swirled and irregular growth features in this Ramaura synthetic ruby. Magnified 40x.

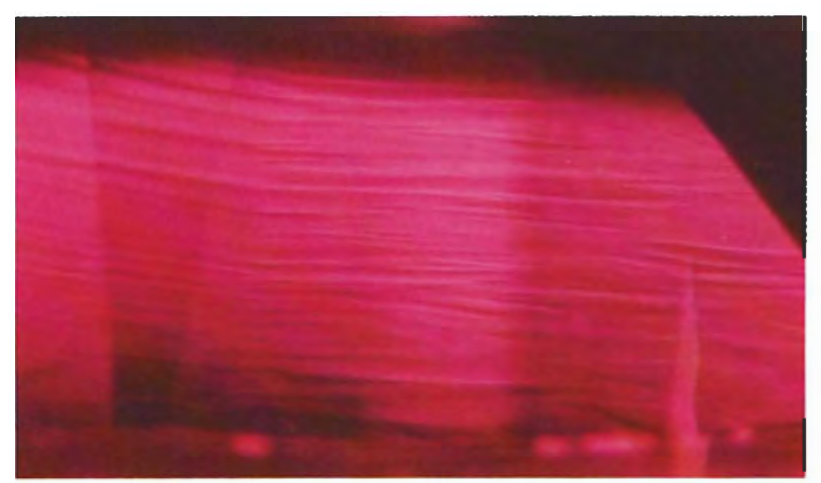

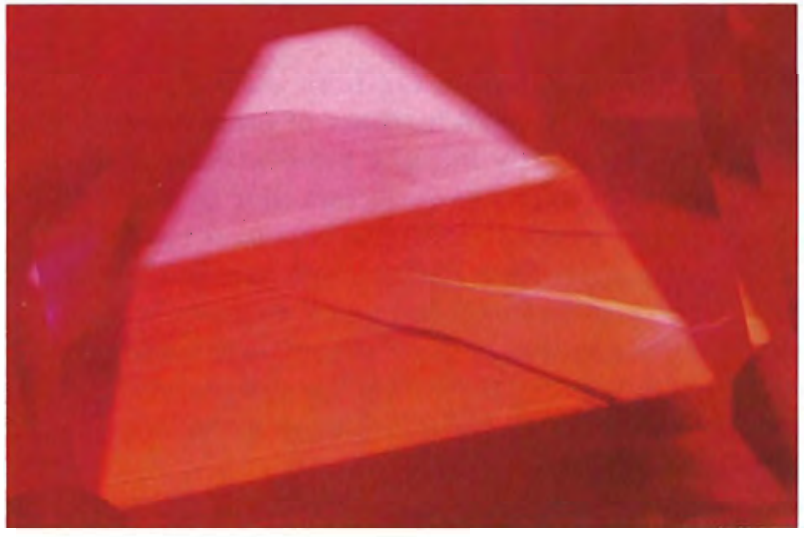

Figure 22. This Ramaura synthetic ruby is host to several different forms of growth features and color zoning. Dark-field illumination and shadowing, magnified $20 x$.

Figure 23. Prominent color zoning is revealed in this Ramaura synthetic ruby by placing a diffuser over dark-field illumination. Magnified $15 \times$.

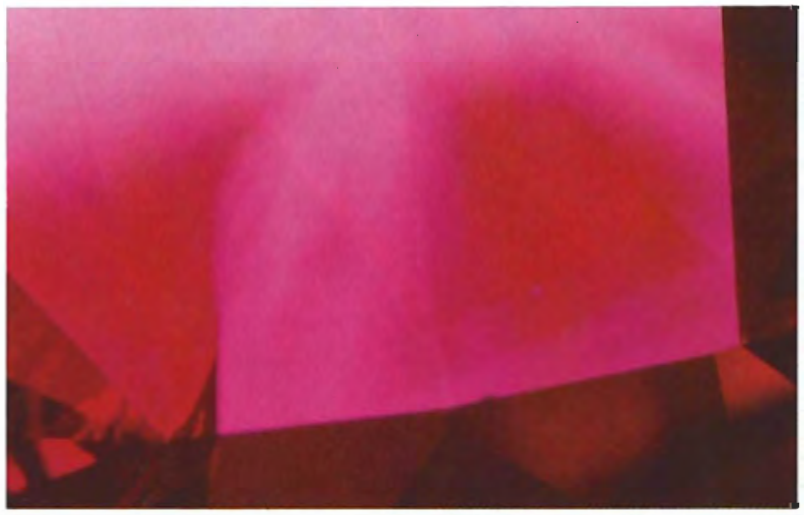




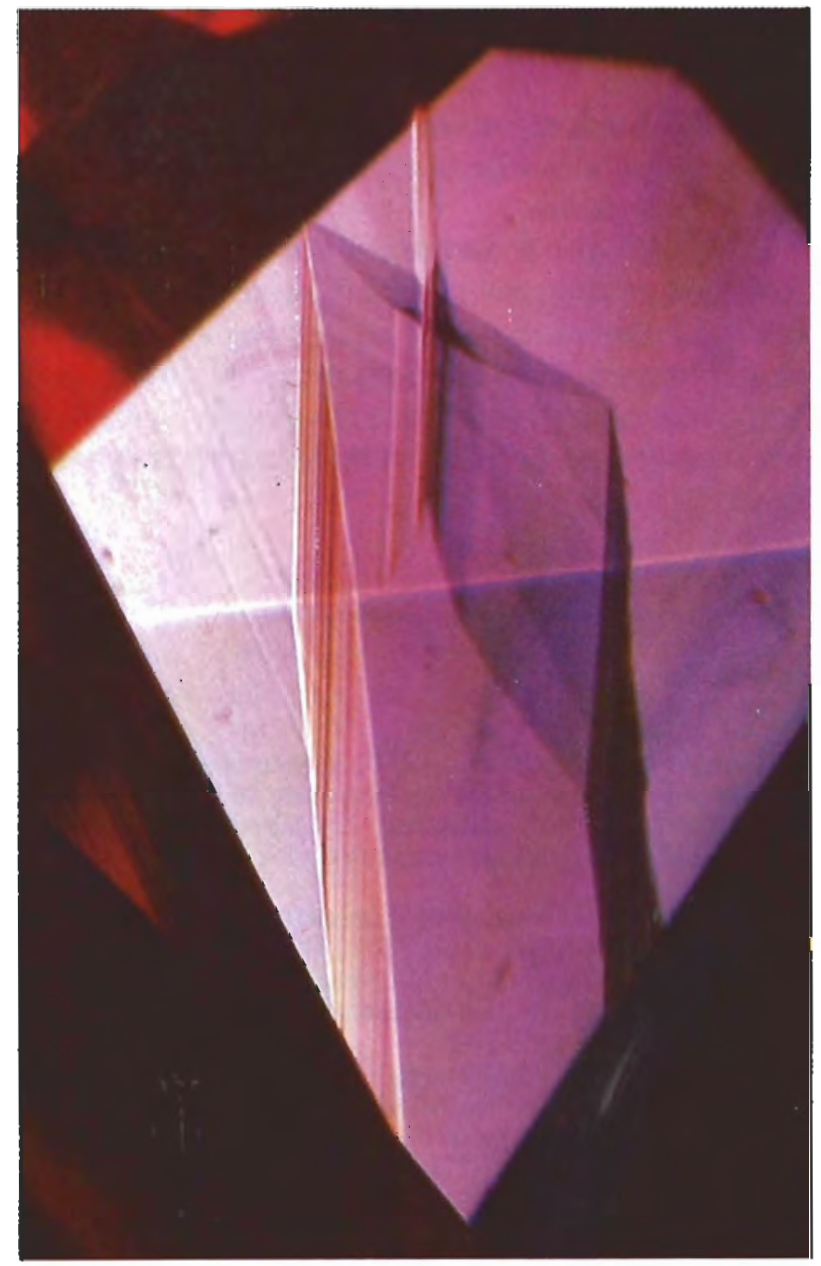

Figure 24. Several forms of color zoning and growth features extend deep within the interior of this Ramaura synthetic ruby. Dark-field, oblique illumination and shadowing. Magnified $40 \times$

observed in the Ramaura synthetic ruby: various forms of flux, particularly distinctive orange-yellow flux and white flux "fingerprints"; in some stones, fractures and healed fractures; and numerous forms of growth features and color zoning. "Comet tail" inclusions were observed in a few stones. The fractures and healed fractures should not be considered diagnostic, while the flux, growth features, color zones, and comet tails in many cases can provide the gemologist with conclusive proof of synthesis.

Although some of the Ramaura synthetic rubies are readily identifiable, others may be particularly difficult to distinguish from their natural counterparts. If, however, the modestly equipped professional gemologist makes the effort to thoroughly familiarize himself or herself

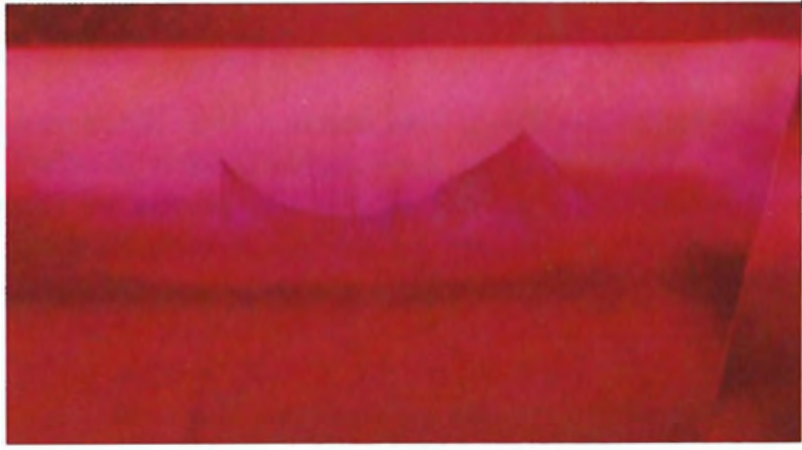

Figure 25. Curved and straight growth features associated with color zoning in a Ramaura synthetic ruby. Diffused and fiber-optic illumination, magnified $30 \times$.

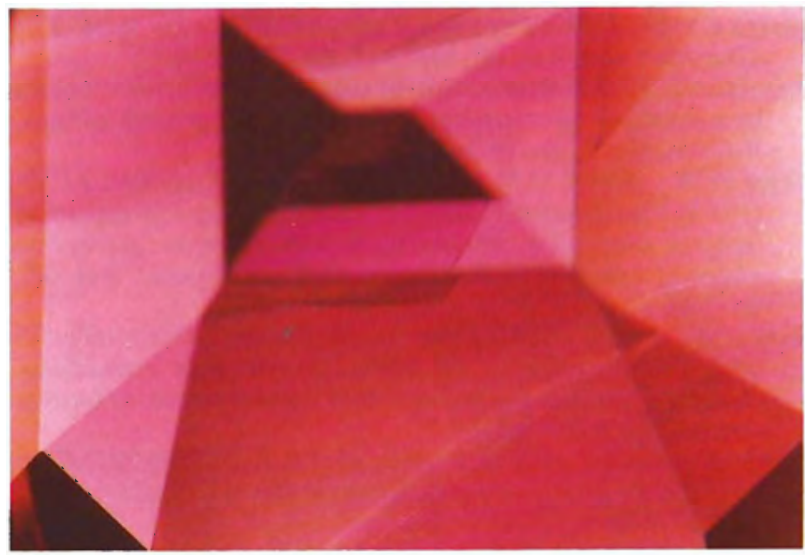

Figure 26. Diffused illumination accentuates different forms of color zoning and growth features in this Ramaura synthetic ruby. Magnified $15 \times$

with the inclusions that are characteristic of this new synthetic ruby as well as with those typical of natural rubies, and employs meticulous study of even the most subtle internal characteristics, he or she should be able to identify this new material. Perhaps equally important is the ability to recognize problem stones (clean material that is questionable), and in these situations obtain a second opinion, whether it be from another experienced gemologist or from a qualified independent gemological laboratory.

In the event that entirely flawless material is encountered in the trade, sophisticated techniques such as neutron activation analysis (Fesq et al., 1973; D.V. Manson and J.E. Shigley, personal communication) and energy dispersive spectrophotometry-X-ray fluorescence (EDS- 
XRF) analysis (Hänni and Stern, 1982; Stern and Hänni, 1982) may be required. These and other techniques can reveal subtle variations in the trace-element content of the material that may help determine the specific growth environment.

High-resolution spectrophotometric analysis of the ultraviolet (Bosshart, 1982), visible light, and infrared portions of the spectrum, in addition to fluorescence spectra (Schwarz, 1977), are also currently being investigated to determine if subtle differences between natural and synthetic gem materials can be used as diagnostic criteria for identification.

Although these and other tests have thus far produced ambiguous results in some areas, investigations continue in the search for a means of identifying entirely flawless material and developing testing methods that the jeweler/gemologist can use to conclusively identify this synthetic.

\section{REFERENCES}

Barta C. (1957) Why synthetic corundum boules split. The Gemmologist, Vol. 26, No. 317, pp. 219-224.

Bosshart G. (1982) Distinction of natural and synthetic rubies by ultraviolet spectrophotometry. Jounal of Gemmology, Vol. 18, No. 2, pp. 145-160.

Fesq H.W., Bibby D.M., Sellschop J.P.F., Watterson J.I.W. (1973) The determination of trace element impurities in natural diamonds by instrumental neutron activation analysis. Journal of Radioanalytical chemistry, Vol. 17, pp. 195-216.

Frémy E., Feil C. (1877) Sur la production artificielle du corindon de rubis et de différents silicates cristallisés. Comptes Rendus des Séances de l'Academie des Sciences, Vol 85, pp. 1029-1035.

Fryer C., Crowningshield R., Hurwit K., Kane R. (1981) Gem Trade Lab notes - synthetic ruby. Gems \& Gemology, Vol. 17, No. 3, pp. 163-165.

Gübelin E.J. (1982) New synthetic rubies made by Professor P. O. Knischka. Gems $\Theta$ Gemology, Vol. 18, No. 3, pp. $165-168$.

Guibelin E.J. (1983) The recognition of the new synthetic rubies. Journal of Gemmology, Vol. 18, No. 6, pp. 477 499.

Hänni H.A., Stern W.B. (1982) Über die gemmologische Bedevtung des Gallium-Nachweises in Korunden. Zeitschrift der Deutschen Gemmologischen Gesellschaft, Vol. 31, No. 4, pp. 260-262.

Kane R.E. (1979) Developments and highlights of GIA's Lab in Los Angeles - synthetic rubies. Gems $\Leftrightarrow$ Gemology,
Vol. 16, No. 7, pp. 206-208

Knischka P.O., Gübelin E. (1980) Synthetische rubine mit Edelsteinqualität, isometrischem Habitus und hoher Zahl unbeschädigter Kristallflächen. Zeitschrift der Deutschen Gemmologischen Gesellschaft, Vol. 29, No. 3/4, pp. 155185.

Koivula J.I. (1981) Photographing inclusions. Gems \& Gemology, Vol. 17, No. 3, pp. 132-142.

Koivula J.I. (1982a) Pinpoint illumination: a controllable system of lighting for gem microscopy. Gems \& Gemology, Vol. 18, No. 2, pp. 83-86

Koivula J.I. (1982b) Shadowing: a new method of image enhancement for gemological microscopy. Gems $\Leftrightarrow$ Gemology, Vol. 18, No. 3, pp. 160-164.

Liddicoat R.T. Jr. (1977) Handbook of Gem Identification, 10th ed. Gemological Institute of America, Santa Monica, CA.

Maiman T.H. (1960) Simulated optical radiation in ruby. Nature, Vol. 187, pp. 493-494.

Mallas A.A. (1979) Kashan-creators of beauty. Lapidary Journal, Vol. 33, No. 6, pp. 1302-1303.

Nassau K. (1980) Gems Made by Man. Chilton Book Co., Radnor, PA.

Schwarz D. (1977) Die Bedeutung der Fluoreszenz fur die Edelsteinuntersuchung. Uhren, Juwelen, Schmuck, Vol. 19 , pp. 52-55.

Stern W.B., Hänni H.A. (1982) Energy dispersive X-ray spectrometry: a nondestructive tool in gemmology. Journal of Gemmology, Vol. 18, No. 4, pp. 285-296. 